\title{
Thermohydraulic Performance of a Series of In-Line Noncircular Ducts in a Parallel Plate Channel
}

\author{
Siddharth D. Mhaske, ${ }^{1}$ Soby P. Sunny, ${ }^{1}$ Sachin L. Borse, ${ }^{2}$ and Yash B. Parikh ${ }^{1}$ \\ ${ }^{1}$ Department of Mechanical Engineering, Symbiosis Institute of Technology, Pune 412 115, India \\ ${ }^{2}$ Department of Mechanical Engineering, Rajarshi Shahu College of Engineering, Pune 411 033, India
}

Correspondence should be addressed to Siddharth D. Mhaske; mhaskesiddharth@gmail.com

Received 28 May 2014; Revised 12 August 2014; Accepted 20 August 2014; Published 21 September 2014

Academic Editor: Shou-Shing Hsieh

Copyright (C) 2014 Siddharth D. Mhaske et al. This is an open access article distributed under the Creative Commons Attribution License, which permits unrestricted use, distribution, and reproduction in any medium, provided the original work is properly cited.

\begin{abstract}
Heat transfer and fluid flow characteristics for two-dimensional laminar flow at low Reynolds number for five in-line ducts of various nonconventional cross-sections in a parallel plate channel are studied in this paper. The governing equations were solved using finite-volume method. Commercial CFD software, ANSYS Fluent 14.5, was used to solve this problem. A total of three different nonconventional, noncircular cross-section ducts and their characteristics are compared with those of circular cross-section ducts. Shape-2 ducts offered minimum flow resistance and maximum heat transfer rate most of the time. Shape- 3 ducts at $\operatorname{Re}<100$ and Shape- 2 ducts at $\operatorname{Re}>100$ can be considered to give out the optimum results.
\end{abstract}

\section{Introduction}

The heat transfer enhancement in most of the engineering applications is a never ending process. The need for better heat transfer rate and low flow resistance has led to extensive research in the field of heat exchangers. Higher heat transfer rate and low pumping power are desirable properties of a heat exchanger. The duct shape and its arrangement highly influence flow characteristics in a heat exchanger. Flow past cylinders, especially circular, flat, oval, and diamond arranged in a parallel plate channel, were extensively studied by Bahaidarah et al. [1-3]. They carried domain discretization in body-fitted coordinate system while the governing equations were solved using a finite-volume technique. Chhabra [4] studied bluff bodies of different shapes like circle, ellipse, square, semicircle, equilateral triangle, and square submerged in non-Newtonian fluids. Kundu et al. $[5,6]$ investigated fluid flow and heat transfer coefficient experimentally over a series of in-line circular cylinders in parallel plates using two different aspect ratios for intermediate range of Re 220 to 2800. Grannis and Sparrow [7] obtained numerical solutions for the fluid flow in a heat exchanger consisting of an array of diamond-shaped pin fins. Implementation of the model was accomplished using the finite element method. Tanda [8] performed experiments on fluid flow and heat transfer for a rectangular channel with arrays of diamond shaped elements. Both in-line and staggered fin arrays were considered in his study. Jeng [9] experimentally investigated pressure drop and heat transfer of an in-line diamond shaped pin-fin array in a rectangular duct. Terukazu et al. [10] studied the heat transfer characteristics and flow behaviours around an elliptic cylinder at high Reynolds number. Gera et al. [11] numerically investigated a two-dimensional unsteady flow past a square cylinder for the Reynolds number (Re) considered in the range of 50-250. The features of the flow past the square cylinder were observed using CFD. Olawore and Odesola [12] numerically investigated two-dimensional unsteady flow past a rectangular cylinder. The effect of vortical structure and pressure distribution around the section of rectangular cylinders are studied in their work. Chen et al. $[13,14]$ analysed flow and conjugate heat transfer in a high-performance finned oval tube heat exchanger element and calculated them for a thermally and hydrodynamically developing three-dimensional laminar flow. Computations were performed with a finite-volume method based on the SIMPLEC algorithm. 
Zdravistch et al. [15] numerically predicted fluid flow and heat transfer around staggered and in-line tube banks and found out close agreement experimental test cases. Tahseen et al. [16] conducted numerical study of the two-dimensional forced convection heat transfer across three in-line flat tubes confined in a parallel plate channel, the flow under incompressible and steady-state conditions. They solved the system in the body-fitted coordinates (BFC) using the finitevolume method (FVM). Gautier et al. [17] proposed a new set of boundary conditions to improve the representation of the infinite flow domain.

Conventional tube/duct shapes have been investigated for fluid flow and heat transfer characteristics. In this paper, twodimensional, steady state, laminar flow over nonconventional noncircular (Shape-1, Shape-2, and Shape-3) in-line ducts confined in a parallel plate channel is considered. The different geometries investigated are Circular, Shape-1, Shape-2, and Shape-3. Only representative cases are discussed in this paper.

\section{Mathematical Formulation}

The governing mass, momentum, and energy conservation equations [1] for steady incompressible flow of a Newtonian fluid are expressed as

$$
\begin{gathered}
\text { Mass conservation: } \nabla \cdot \vec{V}=0 \\
\text { Momentum conservation: } \vec{V} \cdot(\nabla \vec{V})=-\nabla p+v \nabla^{2} \vec{V} \\
\text { Energy conservation: } \rho C_{p} \vec{V} \cdot(\nabla T)=k \nabla^{2} T .
\end{gathered}
$$

Commercial CFD software, ANSYS Fluent 14.5, was used to solve the governing equations. The pressure-velocity coupling is done by semi-implicit method for pressure linked equations (SIMPLE) scheme.

The grid for all the cases is generated using the Automatic Method with all Quadrilateral elements in the Mesh Component System of the ANSYS Fluent 14.5 software. In the numerical simulation, the grid of 11,000 nodes is found to be fair enough for grid independent solution. Refining the grid proved to be unnecessary, resulting in utilizing more computer resources. Figure 2 shows the grid generated for all the configurations.

\section{Geometric Configuration}

A total of four different duct cross-sections, namely, Circular, Shape-1, Shape-2, and Shape-3 were analysed. The five inline ducts were confined in a parallel plate channel. The distance between two consecutive ducts was kept constant. $H / D, L / D$, and $l / D$ ratio (shown in Figure 1 ) kept constant for all cross-sections of the ducts. The height of obstruction is kept constant; that is, the diameter $(D)$ of circular crosssection duct is taken for all the other cross-sections (see Figure 1). The unobstructed length of the pipe before the first and the last module is kept as one module length and three module lengths, respectively, so that the flow is fully developed. It is also ensured that the flow is fully developed when it enters the channel. The ducts and the parallel plate channel walls were assumed to be of infinite extent in the $z$ direction, that is, perpendicular to the paper. Hence, the flow could be considered as two-dimensional. Since, the geometry is symmetric along the $x$-axis, only the lower half portion is considered for the computation purpose.

\section{Boundary Conditions}

Figure 3 represents the schematic of the boundary conditions for all the cross-sections used. A fully developed flow with velocity profile $\left(u=U_{\text {in }}\right)$ and with temperature $\left(T=T_{\text {in }}\right)$ was assigned for the flow at inlet. The temperature was kept different from that of the plate and duct walls. A no slip $(u=$ $v=0$ ) boundary condition was given to the plate and duct surface. The surface temperatures of the plates and the ducts were taken to be constant $\left(T=T_{w}\right)$. At the symmetry, normal component of velocity and normal gradient of other velocity components were taken as zero. At the outflow boundary, there is no change in velocity across boundary.

\section{Validation}

The parallel plate channel problem corresponds to the rectangular duct with infinite aspect ratio. The calculated value of Nusselt number is 7.541. Comparing the calculated Nusselt number with that of the theoretical Nusselt number value of 7.54 [18] shows that our computed values are in good agreement with those of the theoretical values.

Using the geometric parameters $L / D=3$ and $H / D=$ 2 for circular cross-section, the normalized pressure drop $\left(\Delta p^{*}\right)$, and Nusselt number for third module of the parallel plate channel, when compared with the values of Kundu et al. [5], shows good agreement between both the values.

\section{Results and Discussions}

The numerical simulation was carried out for Reynolds number ranging from 25 to 350 and Prandtl number was taken as 0.74 .

6.1. Onset of Recirculation. For any duct shape, no separation of flow was observed below $\mathrm{Re}=30$. Circular duct displayed the signs of recirculation at the lowest $\operatorname{Re}$ value $(\operatorname{Re}=32)$ [1]. The Shape-1 ducts displayed the onset of recirculation at Re value of 48; Shape-2 ducts showed the signs of onset of recirculation at $\operatorname{Re}=60$, while the Shape- 3 showed the signs of recirculation just under $\mathrm{Re}=40$.

As the values of Reynolds number are increased, the recirculation region starts increasing. At $\mathrm{Re}=150$, the length of the recirculation region is slightly smaller than the distance between the two consecutive ducts in the flow direction, while, at $\mathrm{Re}=350$, the length of the recirculation region is greater than the distance between the two consecutive ducts. Since there is no obstruction to the flow downstream of the last duct, the elliptic behaviour of the flow is observed as shown in Figures 5-8. 


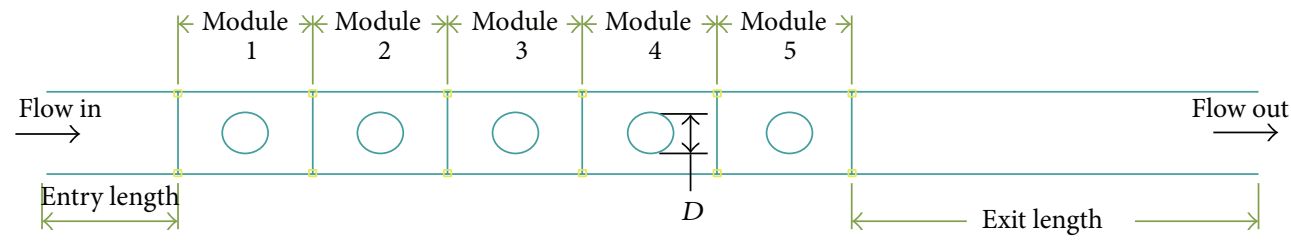

(a)

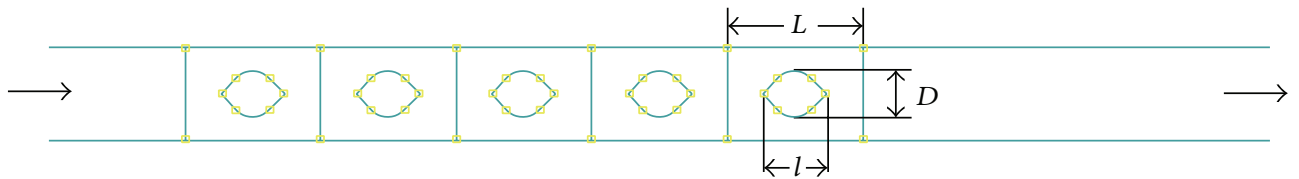

(b)

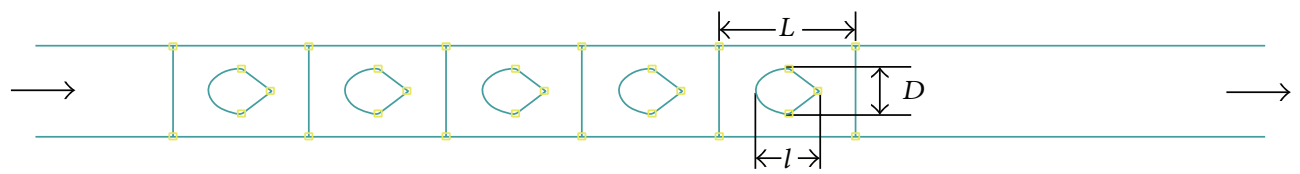

(c)

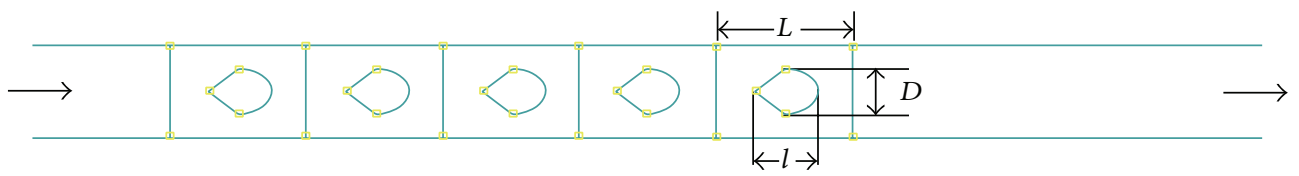

(d)

FIgURE 1: Various duct cross-sections studied in this work: (a) Circular cross-section ducts, (b) Shape-1 cross-section ducts, (c) Shape-2 cross-section ducts, (d) Shape-3 cross-section ducts.
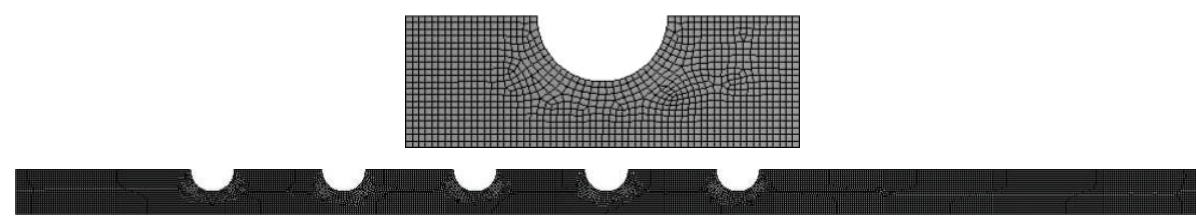

(a)

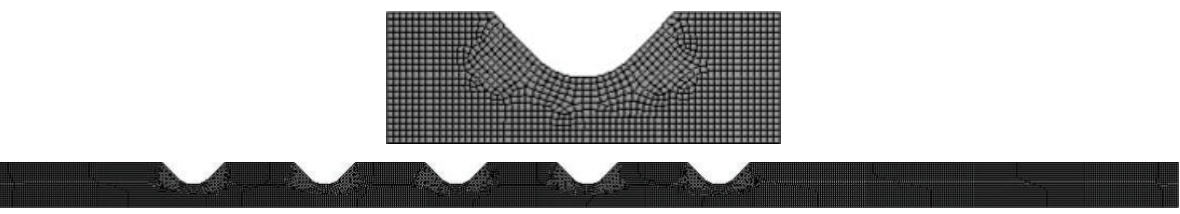

(b)

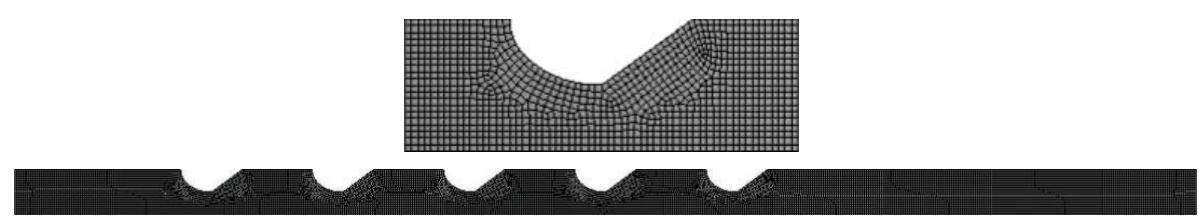

(c)

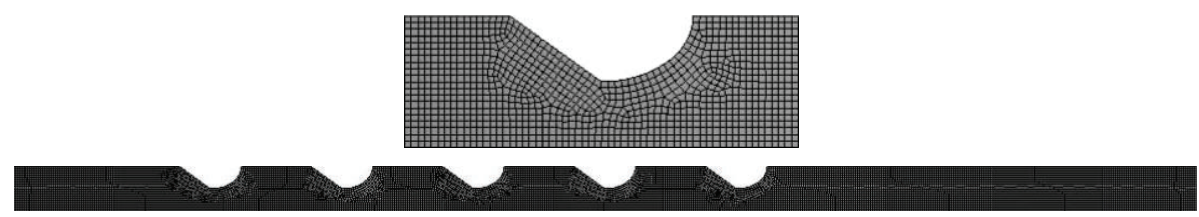

(d)

Figure 2: Grid for geometries considered: (a) Circular cross-section ducts, (b) Shape-1 cross-section ducts, (c) Shape-2 cross-section ducts, (d) Shape-3 cross-section ducts. 


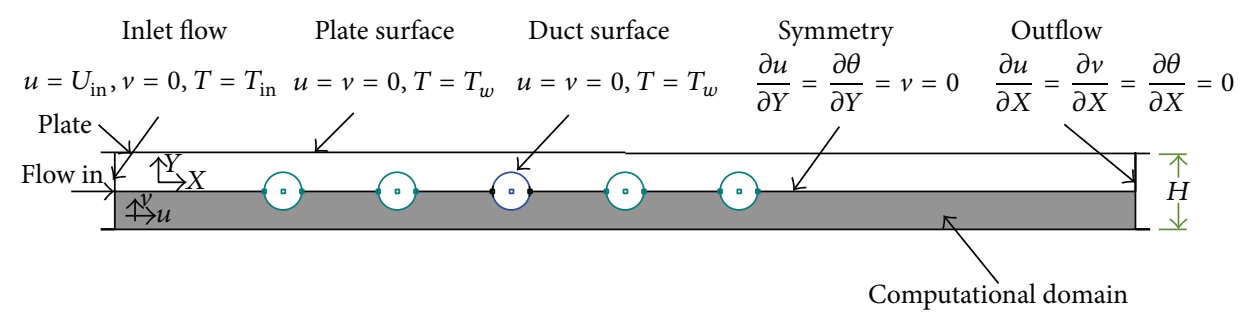

FIgURE 3: Flow domains studied in this study with the boundary condition.

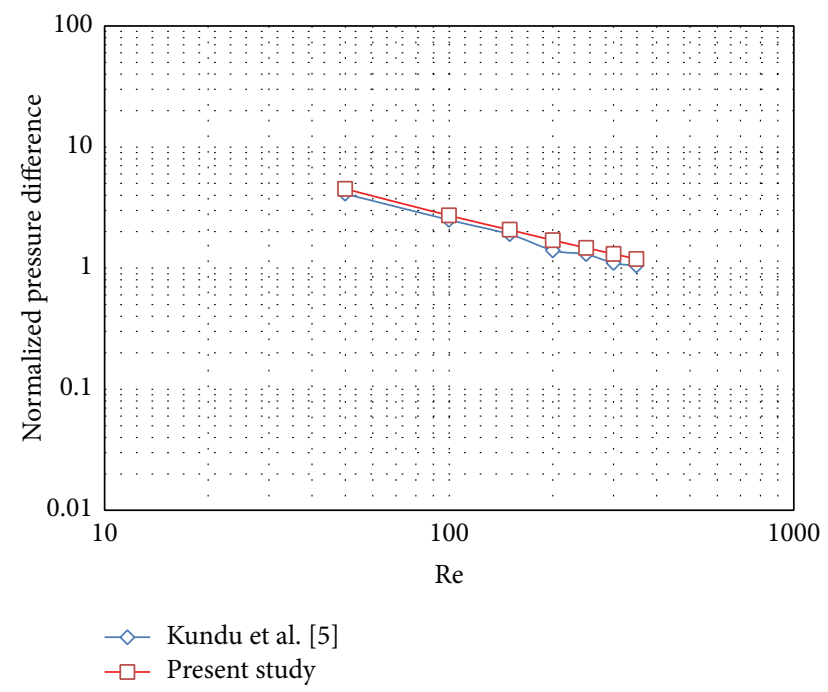

FIGURE 4: Validation with previous work of Kundu et al. [5]: normalized pressure drop across third module.

6.2. Fluid Flow Characteristics. From Figures 5, 6, 7, and 8, we can observe that the streamlines past the ducts 1-4 are similar in nature. Thus, the stream-wise velocity distributions at the module inlets (see Figure 9) and normalized pressure drop Figure 4 and module average Nusselt number for each module (Table 2 ) confirm the existence of periodically fully developed flow downstream of the second module. As the flow is periodically fully developed for the inner modules, it is sufficient to study one inner module so as to understand the essential of flow physics. In present study, we have selected module 3. Small variations for the first and the last modules are observed due to the end effects.

Figure 10 shows the normalized (dimensionless) pressure drop $\left(\Delta p^{*}\right)$ as a function of Reynolds number. We can observe that, as the value of Re increases, there is descend in normalized pressure drop for all the ducts presented in this study.

The ratio of normalized pressure drop for noncircular duct module $\left(\Delta p^{*}\right)$ to that for the circular duct module $\left(\Delta p_{0}^{*}\right)$ is shown in Figure 11. The Shape-1 ducts present pressure drop almost similar to that of the Circular ducts due to their geometric similarity. Shape- 2 ducts present lowest pressure drop ratio $\left(\Delta p^{*} / \Delta p_{0}^{*}\right)$, which means that they offer lower resistance to flow than the circular ducts till $\mathrm{Re}=300$ resulting
TABLE 1: Validation with previous work of Kundu et al. [5]: module average Nusselt number for $L / D=3, H / D=2$.

\begin{tabular}{|c|c|c|c|c|}
\hline & $\operatorname{Re}$ & $\begin{array}{l}\text { Second } \\
\text { module }\end{array}$ & $\begin{array}{l}\text { Third } \\
\text { module }\end{array}$ & $\begin{array}{l}\text { Fourth } \\
\text { module }\end{array}$ \\
\hline Kundu et al. [6] & \multirow{2}{*}{50} & 9.4 & 9.4 & 9.8 \\
\hline Present work & & 9.51 & 9.48 & 9.48 \\
\hline Kundu et al. [6] & \multirow{2}{*}{200} & 12.5 & 12.6 & 12.8 \\
\hline Present work & & 12.68 & 12.63 & 12.64 \\
\hline
\end{tabular}

in lower pumping power requirement. Shape- 3 ducts present lower $\Delta p^{*} / \Delta p_{0}^{*}$ values till $\operatorname{Re}=150$, but, after $\operatorname{Re}=150$, they increase significantly, resulting in more pumping power.

6.3. Heat Transfer Characteristics. Figure 12 presents the module average Nusselt number as a function of Re for module 3 for Shape-1, Shape-2, Shape-3, and Circular ducts Table 1 . The Nusselt number for $\operatorname{Re}<50$ increases rapidly as the Re increases. Till $\mathrm{Re}=50$, there is no significant difference in Nusselt number values for different cross-section ducts, which implies that the duct shape has very little effect on heat transfer rate at $\operatorname{Re}<50$. At higher values of $\mathrm{Re}$ the recirculation of the flow takes place. These recirculation vortices do not transfer heat energy to the main stream of flow. Hence, their contribution to heat transfer is very less. At $\mathrm{Re}<50$, the $\mathrm{Nu}$ is almost the same for various cross-section ducts but, after $\operatorname{Re}=50$, the Nusselt number varies significantly with the cross-section of the duct. Circular cross-section ducts present the least $\mathrm{Nu}$ values till $\mathrm{Re}=250$, while Shape- 2 cross-section ducts present the highest $\mathrm{Nu}$ values after $\operatorname{Re}=250$.

Figure 13 presents the heat transfer enhancement ratio $\left(\mathrm{Nu}^{+}\right)$as a function of Re for module 3 for Shape-1, Shape2 , and Shape- 3 ducts. $\mathrm{Nu}^{+}$is the ratio of Nusselt number for noncircular duct module $(\mathrm{Nu})$ to that for the circular duct module $\left(\mathrm{Nu}_{0}\right)$. It represents how effective the heat transfer rate will be using the noncircular ducts as compared to the circular ducts. For $\mathrm{Re}<50$, all the ducts show similar $\mathrm{Nu}^{+}$ values. Shape- 2 ducts show least $\mathrm{Nu}^{+}$values at $\mathrm{Re}<200$ but, after $\mathrm{Re}=200$, they rise up significantly giving highest $\mathrm{Nu}^{+}$ values as compared to their counter parts. Shape-1 ducts show constant drop in the $\mathrm{Nu}^{+}$values and, at $\mathrm{Re}>250$, they have heat transfer rate less than the circular ducts. 


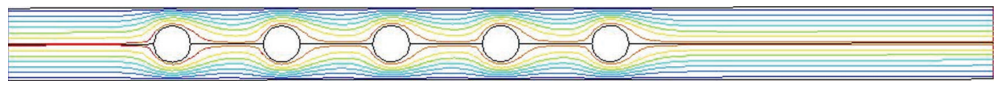

(a)

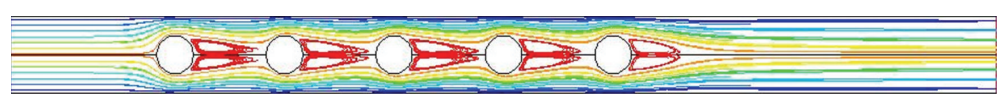

(b)

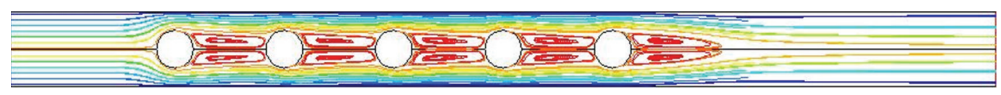

(c)

Figure 5: Effect of Reynolds number on the streamline over Circular cross-section ducts: (a) $\operatorname{Re}=25$, (b) $\operatorname{Re}=150$, and (c) $\operatorname{Re}=300$.

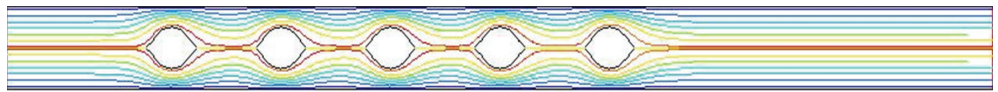

(a)

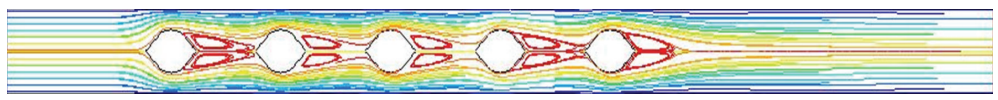

(b)

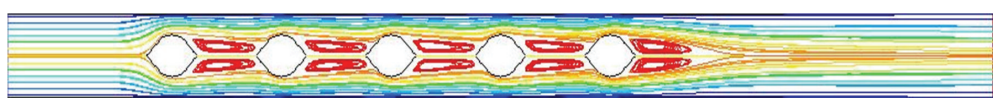

(c)

Figure 6: Effect of Reynolds number on the streamline over Shape-1 cross-section ducts: (a) $\operatorname{Re}=25$, (b) $\operatorname{Re}=150$, and (c) $\operatorname{Re}=300$.

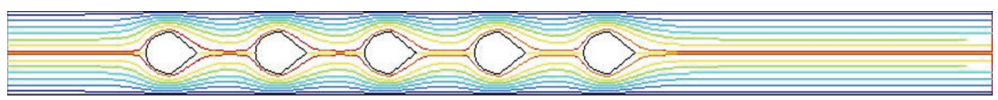

(a)

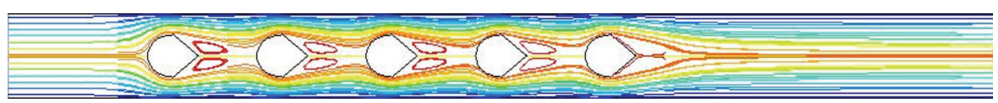

(b)

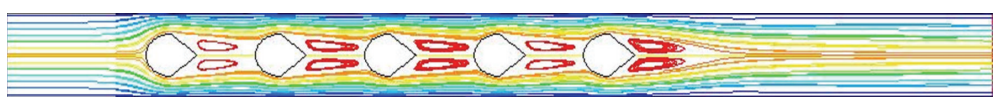

(c)

FIGURE 7: Effect of Reynolds number on the streamline over Shape-2 cross-section ducts: (a) $\operatorname{Re}=25$, (b) $\operatorname{Re}=150$, and (c) $\operatorname{Re}=300$.

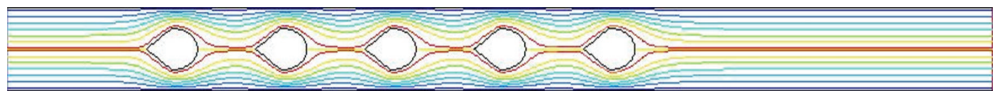

(a)

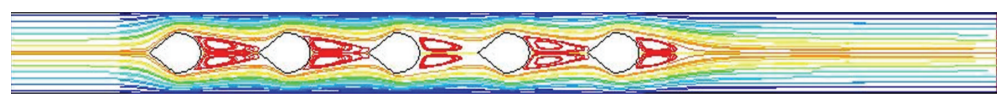

(b)

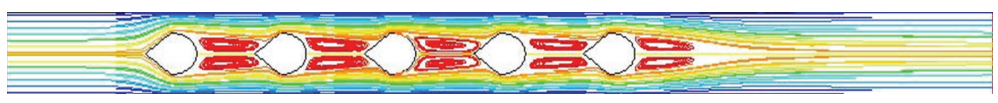

(c)

Figure 8: Effect of Reynolds number on the streamline over Shape-3 cross-section ducts: (a) $\operatorname{Re}=25$, (b) $\operatorname{Re}=150$, and (c) $\operatorname{Re}=300$. 


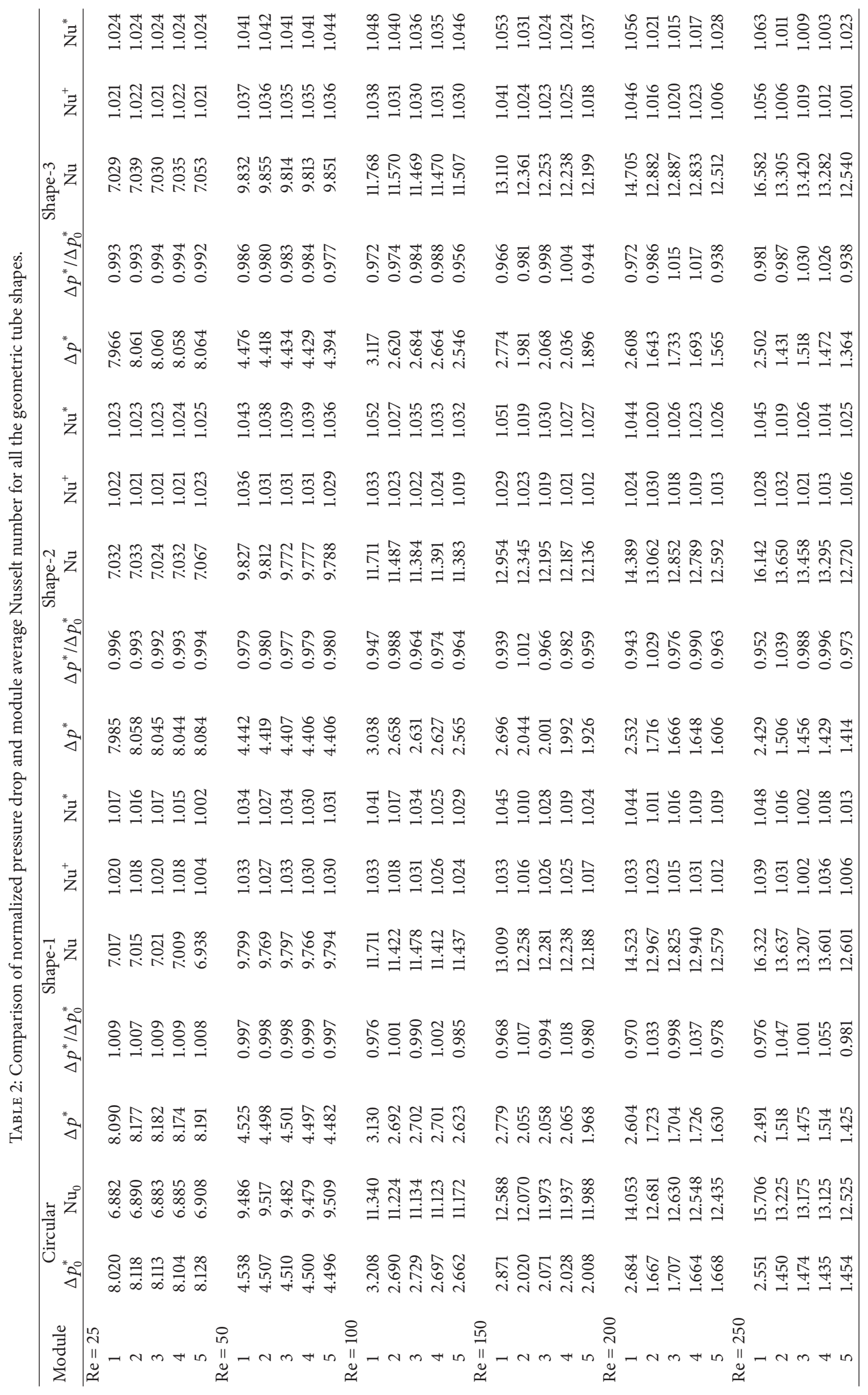




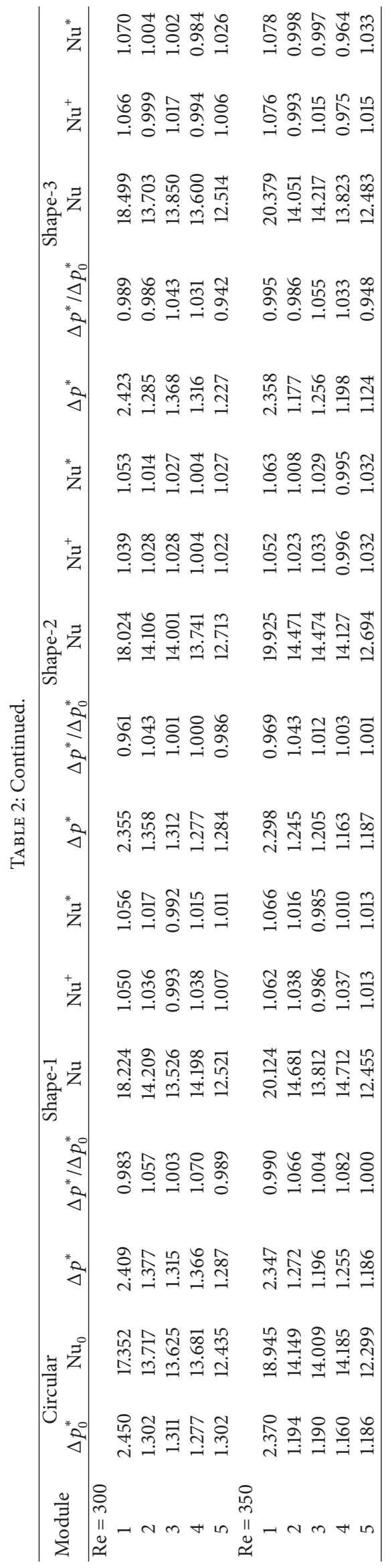




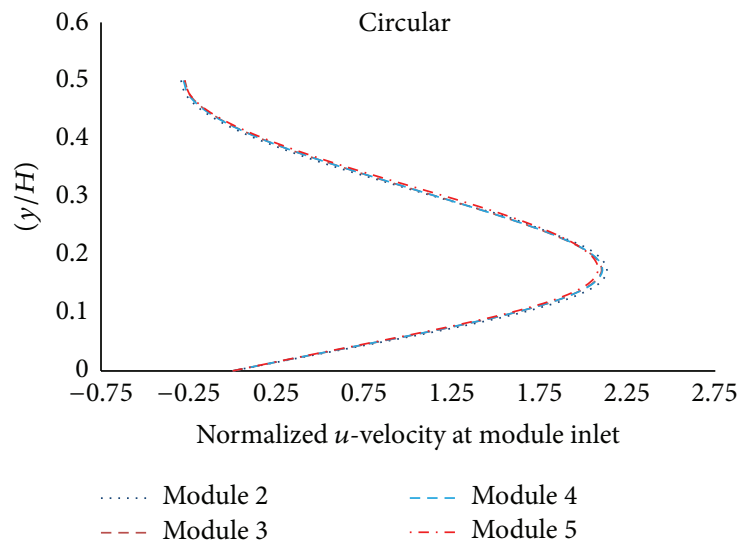

(a)

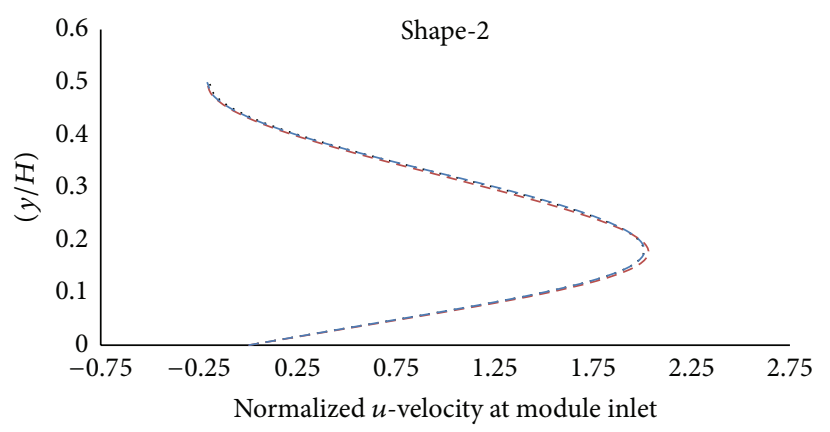

..... Module 2

- - - Module 3

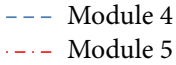

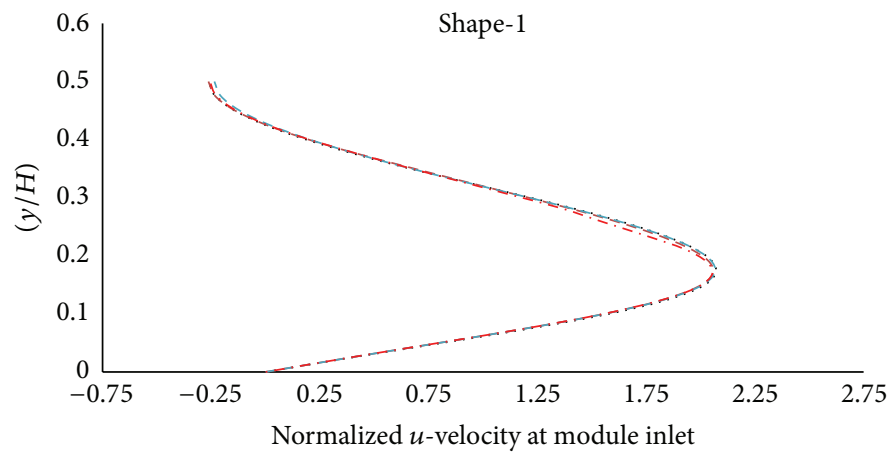

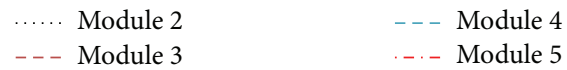

(b)

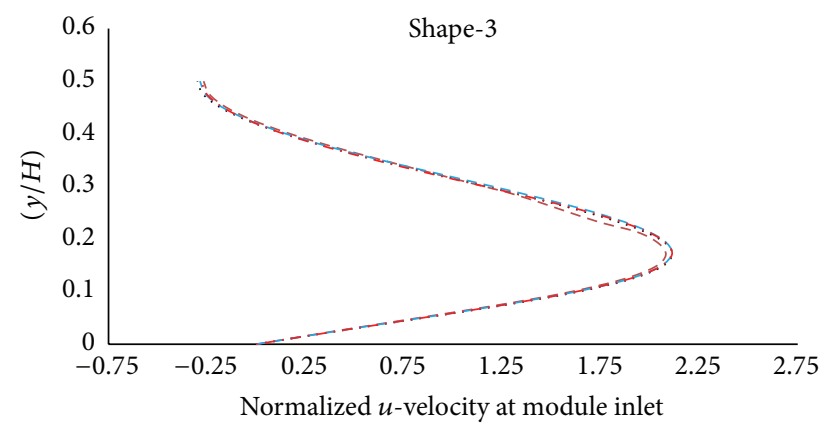

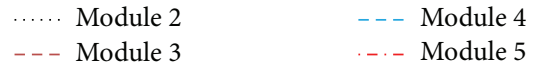

(d)

(c)

FIGURE 9: Normalized $u$-velocity profiles at inlet of modules at $\operatorname{Re}=150$.

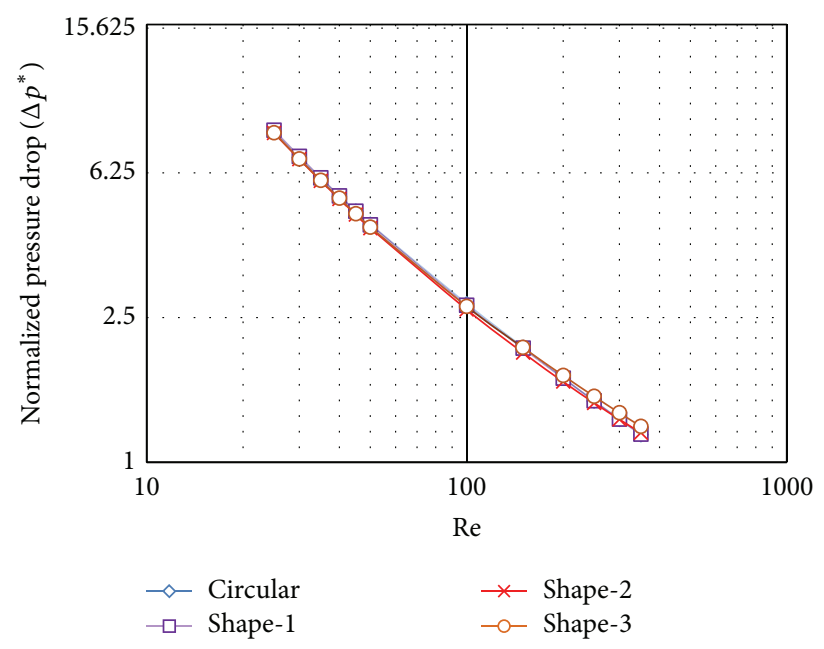

FIGURE 10: Variation of normalized pressure drop $\left(\Delta p^{*}\right)$ with Re for third module. 


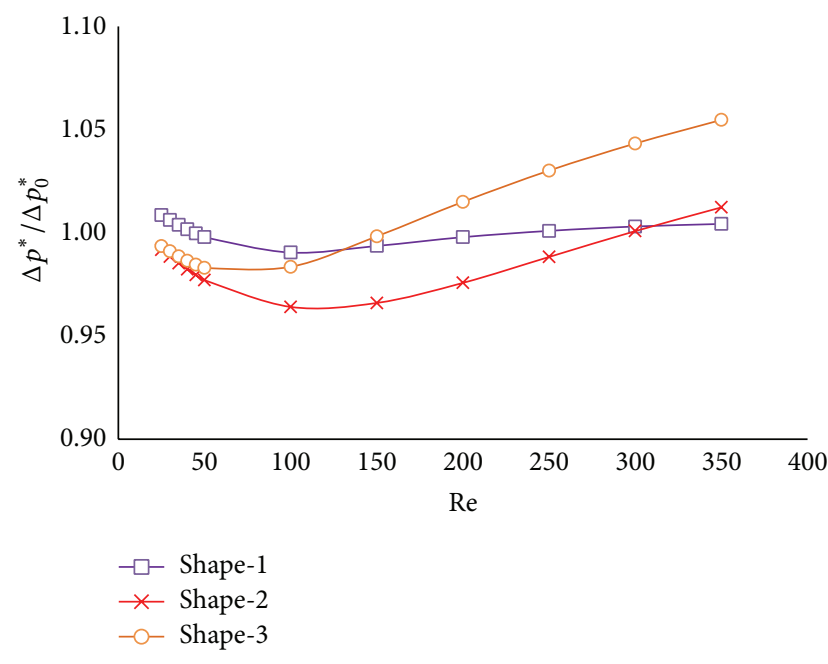

FIgURE 11: Variation of $\Delta p^{*} / \Delta p_{0}^{*}$ with Re for third module.

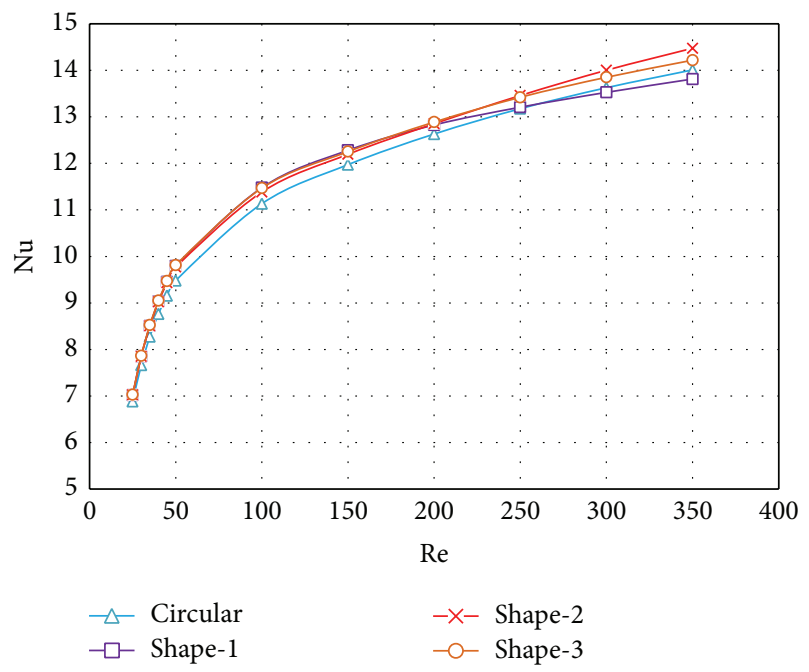

FIGURE 12: Variation of $\mathrm{Nu}$ with Re for third module.

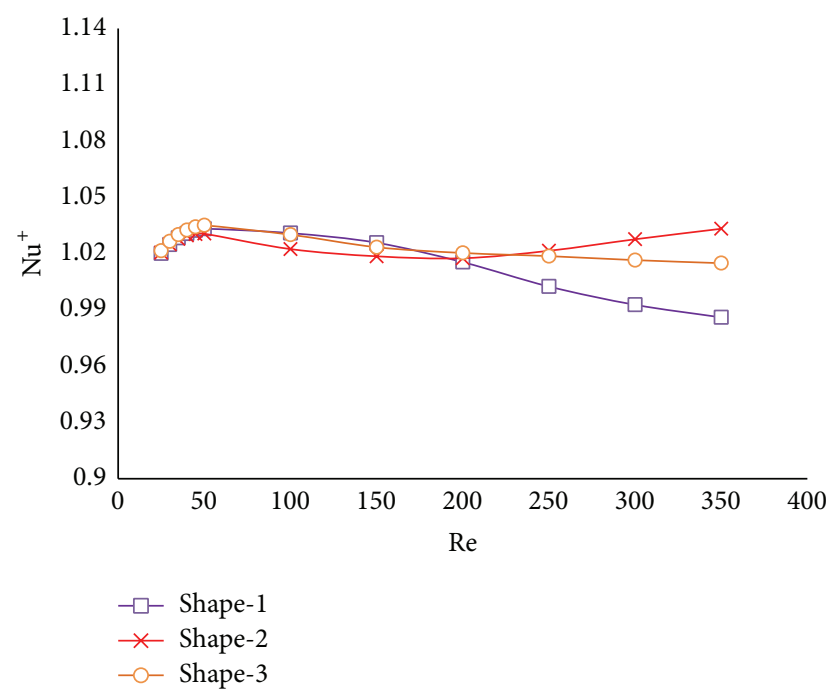

Figure 13: Variation of $\mathrm{Nu}^{+}$with $\mathrm{Re}$ for third module.

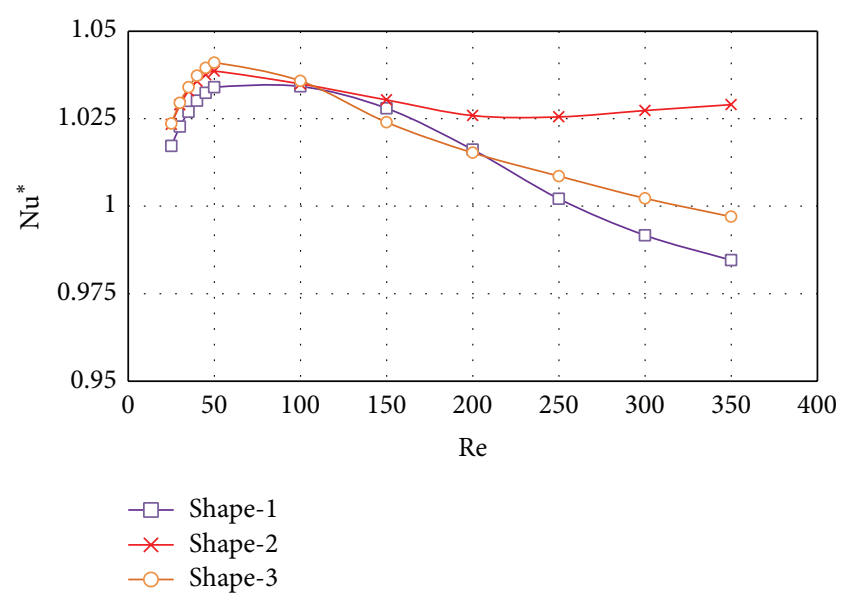

FIGURE 14: Variation of $\mathrm{Nu}^{*}$ with Re for third module.

Figure 14 presents the heat transfer performance ratio $\left(\mathrm{Nu}^{*}\right)$ as a function of Re for module 3 for Shape-1, Shape2 , and Shape-3 ducts. $\mathrm{Nu}^{*}$ represents heat transfer enhancement per unit increase in pumping power. The Shape-1 ducts performed poorly as compared to Circular ducts at Re $>250$. Shape- 3 ducts presented good results at $\mathrm{Re}<100$ but then they presented a constant drop in the $\mathrm{Nu}^{*}$ values, while Shape-2 ducts displayed promising results after $\mathrm{Re}=100$.

\section{Conclusion}

In an environment where the heat transfer rate and pumping power is critical, Shape-2 ducts show promising results as compared to their counterparts. The duct shape has very little influence on the heat transfer rate at low Reynolds number. For optimal design of a heat exchanger for heat transfer enhancement per unit increase in pumping power, Reynolds number and cross-section of the duct must be carefully chosen. So, for heat exchanger, Shape-3 ducts at $\operatorname{Re}<$ 100 and Shape- 2 ducts at $\operatorname{Re}>100$ can be considered to give out the optimum results.

\section{Nomenclature}

A: Area of heat transfer surfaces in a module $\left(\mathrm{m}^{2}\right)$

$C_{p}:$ Specific heat $(\mathrm{J} / \mathrm{kg} \mathrm{K})$

$D$ : Blockage height of a tube inside the channel (m)

$f: \quad$ Module friction factor

$f_{0}$ : Module friction factor for circular tubes

$H$ : Height of the channel (m)

$L: \quad$ Module length (m)

$k$ : Thermal conductivity $(\mathrm{W} / \mathrm{m} \cdot \mathrm{K})$

$l$ : $\quad$ Length of the tube cross-section along the flow direction $(\mathrm{m})$

$\mathrm{Nu}$ Module average Nusselt number $\left(=\dot{m} C_{p} \Delta T_{b} H / k A\left(T_{w}-T_{m}\right)\right)$

$\mathrm{Nu}_{0}$ : Module average Nusselt number for the reference case of circular tubes 
$\mathrm{Nu}^{+}$: Heat transfer enhancement ratio $\left(=\mathrm{Nu} / \mathrm{Nu}_{0}\right)$

$\mathrm{Nu}^{*}$ : Heat transfer performance ratio $\left[=\mathrm{Nu}^{+} /\left(f / f_{0}\right)^{1 / 3}\right]$

$\dot{m}: \quad$ Mass flow rate $(\mathrm{kg} / \mathrm{s})$

p: $\quad$ Pressure $(\mathrm{Pa})$

Re: Reynolds number $(\rho \mathrm{VH} / \mu)$

$T: \quad$ Temperature $(\mathrm{K})$

$T_{m}$ : Average of module inlet bulk temperature and module outlet bulk temperature $(\mathrm{K})$

$T_{w}$ : Temperature of heat transfer surfaces $(\mathrm{K})$

$U_{\text {in }}$ : Velocity at the channel inlet $(\mathrm{m} / \mathrm{s})$

$\vec{V}: \quad$ Velocity field

$y: \quad$ Vertical distance from the channel bottom $(\mathrm{m})$

$\Delta p:$ Pressure drop across a module $(\mathrm{Pa})$

$\Delta p^{*}:$ Normalized pressure drop $\left(=\Delta p / \rho U_{\text {in }}^{2}\right)$

$\Delta T_{b}$ : Change in bulk temperature across a module $(\mathrm{K})$

$\mu: \quad$ Dynamic viscosity $\left(\mathrm{N} \cdot \mathrm{s} / \mathrm{m}^{2}\right)$

$\rho: \quad$ Density

$\nabla: \quad$ Del operator.

\section{Conflict of Interests}

The authors declare that there is no conflict of interests regarding the publication of this paper.

\section{Acknowledgments}

The authors would like to present their sincere gratitude towards the Faculty of Mechanical Engineering in Symbiosis Institute of Technology, Pune, and Rajarshi Shahu College of Engineering, Pune.

\section{References}

[1] H. M. S. Bahaidarah, M. Ijaz, and N. K. Anand, "Numerical study of fluid flow and heat transfer over a series of inline noncircular tubes confined in a parallel-plate channel," Numerical Heat Transfer Part B: Fundamentals, vol. 50, no. 2, pp. 97-119, 2006.

[2] H. M. S. Bahaidarah, N. K. Anand, and H. C. Chen, "A numerical study of fluid flow and heat transfer over a bank of flat tubes," Numerical Heat Transfer A, vol. 48, no. 4, pp. 359385, 2005.

[3] H. M. S. Bahaidarah, A numerical study of heat and momentum transfer over a bank of flat tubes [Ph.D. thesis], Texas A\&M University, College Station, Tex, USA, 2004.

[4] R. P. Chhabra, "Fluid flow and heat transfer from circular and noncircular cylinders submerged in non-newtonian liquids," Advances in Heat Transfer, vol. 43, pp. 289-417, 2011.

[5] D. Kundu, A. Haji-Sheikh, and D. Y. S. Lou, "Heat transfer predictions in cross flow over cylinders between two parallel plates," Numerical Heat Transfer; Part A: Applications, vol. 19, no. 3, pp. 361-377, 1991.

[6] D. Kundu, A. Haji-Sheikh, and D. Y. S. Lou, "Heat transfer in crossflow over cylinders between two parallel plates," Journal of Heat Transfer, vol. 114, no. 3, pp. 558-564, 1992.

[7] V. B. Grannis and E. M. Sparrow, "Numerical simulation of fluid flow through an array of diamond-shaped pin fins," Numerical Heat Transfer A: Applications, vol. 19, no. 4, pp. 381-403, 1991.
[8] G. Tanda, "Heat transfer and pressure drop in a rectangular channel with diamond-shaped elements," International Journal of Heat and Mass Transfer, vol. 44, no. 18, pp. 3529-3541, 2001.

[9] T.-M. Jeng, "Thermal performance of in-line diamond-shaped pin fins in a rectangular duct," International Communications in Heat and Mass Transfer, vol. 33, no. 9, pp. 1139-1146, 2006.

[10] O. Terukazu, N. Hideya, and T. Yukiyasu, "Heat transfer and flow around an elliptic cylinder," International Journal of Heat and Mass Transfer, vol. 27, no. 10, pp. 1771-1779, 1984.

[11] B. Gera, P. K. Sharma, and R. K. Singh, "CFD analysis of 2D unsteady flow around a square cylinder," International Journal of Applied Engineering Research, vol. 1, no. 3, pp. 602-610, 2010.

[12] A. S. Olawore and I. F. Odesola, "2D flow around a rectangular cylinder: a computational study," International Journal of Science and Technology, vol. 2, no. 1, pp. 1-26, 2013.

[13] Y. Chen, M. Fiebig, and N. K. Mitra, "Conjugate heat transfer of a finned oval tube part A: flow patterns," Numerical Heat Transfer A: Applications, vol. 33, no. 4, pp. 371-385, 1998.

[14] Y. Chen, M. Fiebig, and N. K. Mitra, "Conjugate heat transfer of a finned oval tube part B: heat transfer behaviors," Numerical Heat Transfer A, vol. 33, no. 4, pp. 387-401, 1998.

[15] F. Zdravistch, C. A. Fletcher, and M. Behnia, "Numerical laminar and turbulent fluid flow and heat transfer predictions in tube banks," International Journal of Numerical Methods for Heat and Fluid Flow, vol. 5, no. 8, pp. 717-733, 1995.

[16] T. A. Tahseen, M. Ishak, and M. M. Rahman, "A numerical study of forced convection heat transfer over a series of flat tubes between parallel plates," Journal of Mechanical Engineering and Sciences, vol. 3, pp. 271-280, 2012.

[17] R. Gautier, D. Biau, and E. Lamballais, "A reference solution of the flow over a circular cylinder at $R e=40$," Computers \& Fluids, vol. 75, pp. 103-111, 2013.

[18] Y. A. Cengel and A. J. Ghajar, Heat and Mass Transfer: Fundamentals and Applications, Tata McGraw-Hill, 4th edition, 2011. 

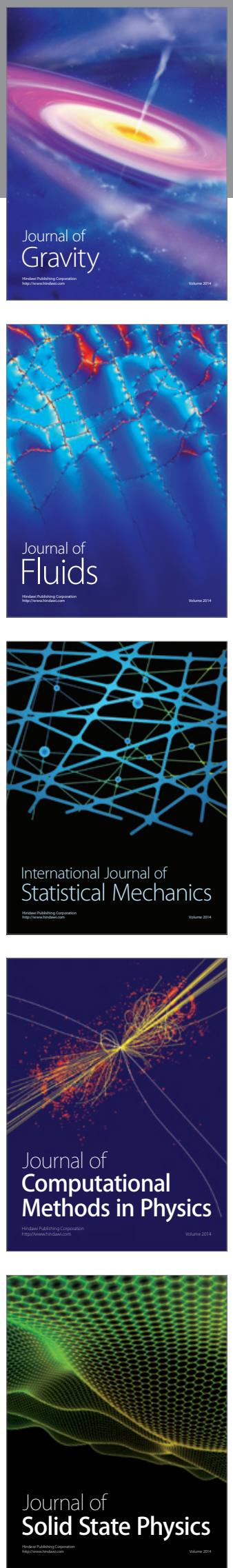

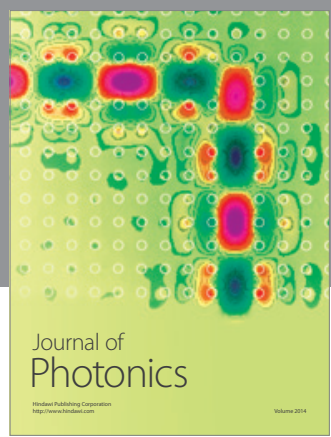

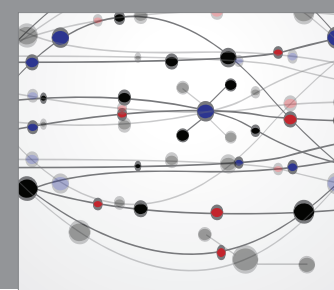

The Scientific World Journal

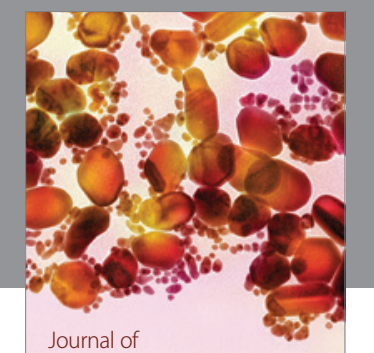

Soft Matter
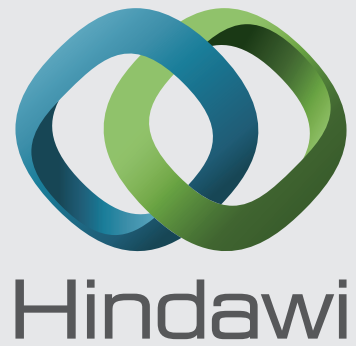

Submit your manuscripts at

http://www.hindawi.com
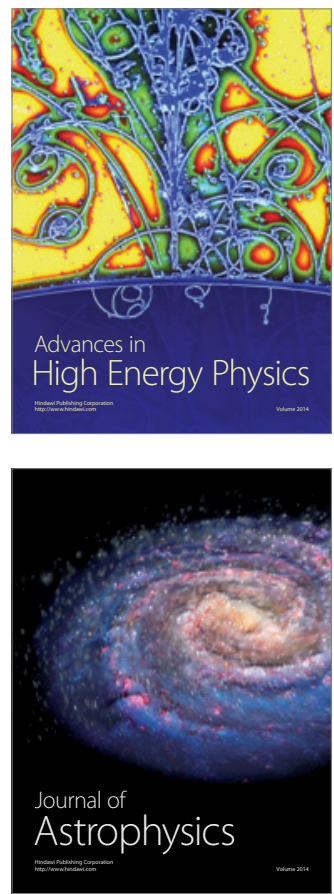
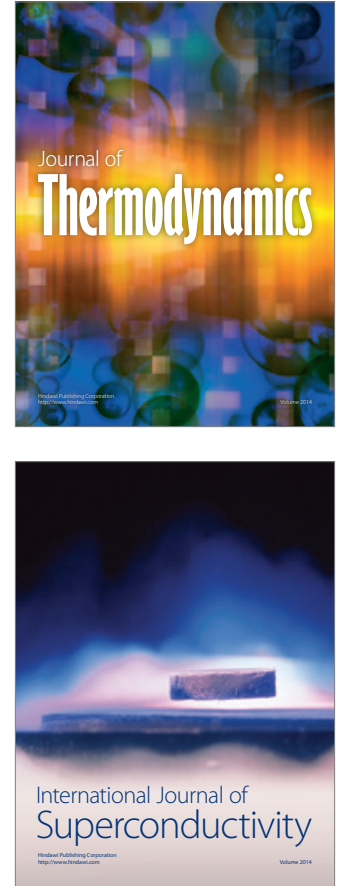
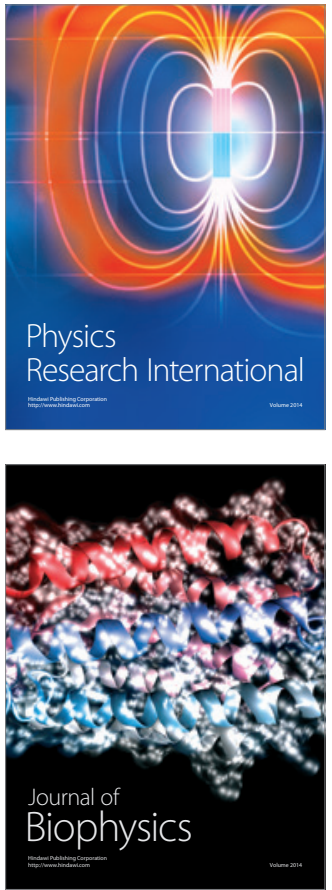
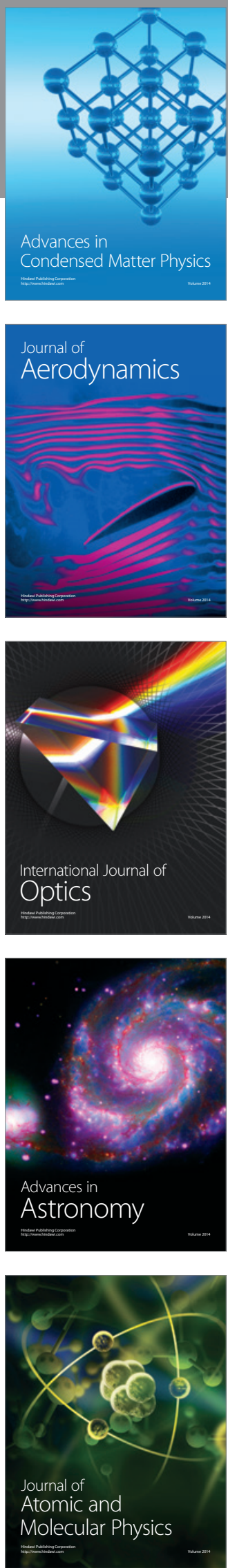